\title{
THE SIENA 25 YEARS EXPERIENCE ON RARE NEUROLOGICAL DISEASES
}

\section{Antonio Federico \\ Department of Neurological Sciences and Behaviour University of Siena}

\begin{abstract}
The 25 years experience in diagnosis and research on rare neurological diseases in Siena is reported. After a brief introduction of the concept of rare neurological diseases and their frequency, the diagnostic strategy and the casuistic is described. The Cerebrotendinous xanthomatosis is reported as an example.
\end{abstract}

Keywords: neurohandicap, rare neurological diseases

\section{INTRODUCTION}

Rare diseases are disorders occurring with a low frequency in the general population. They are therefore somewhat neglected from a scientific and social security perspective. They have been also recently defined as "orphan diseases" because affected patients receive little support from the health systems, little research is devoted to discovering their pathogenesis and the pharmaceutical industry is unwilling to finance studies for development of specific drugs, which would not have a big enough market to guarantee profits on the necessary investment. Some of these diseases are hereditary, some are congenital, others have late onset in adulthood or even in ageing; some of them are transmissible, some can be treated, some are rare in certain countries and endemic in others.

A USA law defines a disease as rare if it affects less than 200,000 US citizens (1/1200 persons). Other countries have narrower definitions. In Europe, the Working Group on Rare Diseases instituted by the Commission of the EU defines rare diseases those affecting less than $5 / 10,000$ persons. In Japan, a rare disease is a disease affecting $4 / 10,000$ persons.

Recent WHO data indicates that at least 5,000 diseases and syndromes can be defined as rare. Most of them (about 4,000) are caused by genetic abnormalities and prevalently affect the nervous system, with involvement also of other systems.

Introducing a conference on rare diseases held in Florence in March 1999, Prof. Garattini stated that "rare diseases and orphan drugs are one of the many unacceptable inequalities of our health system. A patient with a rare disease is twice unfortunate: he has a disease like many others but he has also troubles in finding a doctor expert in his disease. He has the general problem of not having available treatments. Finally, his hopes for the future are not good, as pharmaceutical companies are not interested in developing drugs that have a limited market (orphan drugs)" (1).

There are some general opinions on rare diseases, leading to scepticism of doctors and generally to health workers to develop strategies for diagnosis for these diseases (Table I).

In these years our aim was to give to doctors, students and health providers, at local, regional, national and international levels arguments that the study of such disorders is important to offer to "orphan" patients diagnostic, therapeutic and care possibilities and that it may be considered an interesting research model for understanding more common disorders.

Table I: Common Opinions on Rare Diseases

\begin{tabular}{|l|l|}
\hline Opinions & \multicolumn{2}{l|}{ Comments } \\
\hline Diseases that are rare & $\begin{array}{l}\text { They are rare if considered in singularly, } \\
\text { but are frequent as a group }\end{array}$ \\
\hline The clinical signs are difficult for the diagnosis & $\begin{array}{l}\text { There may exist some guidelines } \\
\text { for the clinical suspicion }\end{array}$ \\
\hline $\begin{array}{l}\text { Laboratory investigations are too sophisticated } \\
\text { and not easily available }\end{array}$ & There exist several first level investigations \\
\hline $\begin{array}{l}\text { It is very hard and time consuming the } \\
\text { investigation strategy in relationship to } \\
\text { the therapeutic possibilities }\end{array}$ & $\begin{array}{l}\text { For many rare diseases therapeutic strategies exist: } \\
\text { they are more effective if started early. It might be usefu } \\
\text { the genetic counselling and also the development } \\
\text { of Scientific knowledge. }\end{array}$ \\
\hline
\end{tabular}

Correspondence to:

Prof. Antonio Federico. Department of Neurological Sciences and Behaviour, Siena University, Italy.

Policlinico "Le Scotte" - Viale Bracci - 53100 - Siena - Italy.

Tel +390577585763- +390577263355 Fax +39057740327

e-mail: federico@unisi.it 


\section{POLITICAL PROGRAMS AND RARE DISEASES}

In 1989, the US Commission on orphan diseases underlined the state of neglect of this group of diseases and listed several priorities. This was a milestone in the recognition of the right to health care of patients with rare diseases.

The priorities accepted by all the developed countries are:

- need for information;

- need for research into pathogenesis;

- need to provide incentives for research and drug development;

- need to ensure adequate health care for all the affected patients.

All the European countries adopted this strategy and the Italian Health Plan 1998-2000 identified rare diseases as one of the major health policy problems, recommending the following actions:

- identification of national referral centers and formation of a network for diagnosis and treatment;

- development of a national research program to improve prevention, diagnosis, health care and therapy; - development of strategies to improve the quality of life of patients;

- development of a program of information for patients and their families;

- development of strategies of action for the production of specific drugs in order to improve therapeutic perspectives.

In the recent years, Tuscany developed a program for diagnosis and therapy of rare diseases, establishing a network of the different hospitals and creating a registry of rare diseases, in which are collected all the patients followed in the Tuscany hospitals. I am personally coordinating the network for Rare neurological diseases.

\section{RARE DISEASES: HOW MANY ARE THERE?}

In 1995, the Physicians' Guide to Rare Diseases (2) the Italian translation Guida alle malattie rare (3), coordinated by myself, was published in 1999 - divided the main rare diseases into various categories and listed the main clinical signs, differential diagnosis, treatment, referring centers in USA. It was the first example of a book on this subject for general practioners (GPs). The Italian version has recently been distributed to all GPs and general practice pediatricians. Table II shows the distribution of rare diseases within the different medical subspecialties.

Table II - Number of rare diseases in the different medical subspecialties.

\begin{tabular}{|c|c|c|c|}
\hline Genetic & 165 & Connective tissue & 40 \\
\hline Neurology & 140 & Endocrinology & 33 \\
\hline Immunology & 84 & Cardiovascular & 31 \\
\hline Metabolic & 70 & Ophthalmology & 26 \\
\hline Hematology & 70 & Gastrointestinal & 20 \\
\hline Dermatology & 58 & Nephrology & 12 \\
\hline
\end{tabular}

\section{RARE NEUROLOGICAL DISEASES}

Due to involvement of the central or peripheral nervous systems or muscle, more than $50 \%$ of rare diseases have symptoms requiring neurological care. Neurologists are therefore the specialists most concerned with correct and immediate diagnosis. They have to be familiar with these disorders and to develop a correct approach to patient management (Table III).

Table III - Number of diseases

with neurological involvement.

\begin{tabular}{ll}
\hline Neurological Involvement & $401 / 749$ \\
\hline No Neurological Involvement & $348 / 749$ \\
\hline
\end{tabular}

The general attitude of families, patients and the health System (family doctors, specialists, hospital doctors) is almost always characterized by a resignation to the situation, by the idea that diagnosis is useless since no therapy exists. Correct diagnosis is frequently regarded as an academic exercise because the causes of neurodegeneration cannot be treated.

Here we report our experience in a reference centre for rare neurological diseases (Neurometabolic Disease Unit, Research Centre for the Diagnosis, Therapy and Prevention of Neurohandicaps and Rare Neurological Diseases, University of Siena) that receives patients from various regions of Italy. In the case of neurogenetic diseases, it is possible in many cases to identify healthy carriers and perform prenatal diagnosis in families at risk.

\section{RESEARCH CENTRE FOR THE DIAGNOSIS, THERAPY AND PREVENTION OF NEURO- HANDICAPS AND RARE NEUROLOGICAL DIS- EASES, UNIVERSITY OF SIENA}

This centre was founded some years ago by a pool of scientists interested in rare diseases. Its foundation was prompted by the need to offer complete (not only neurological) care to patients with rare diseases. Like other similar centers, we found that even minor health problems can be the source of difficulties in the care of these patients since both families and family doctors are poorly informed about them. A normal medical problem, easily resolved in patients with common diseases, often triggers a series of management problems in patients with rare diseases.

Our staff offers a broad spectrum of expertise, enabling the problem of neurological disabilities to be approached in a coordinated way.

The diagnostic approach consists of traditional clinical methods focusing on personal and family medical history, inheritance, evolution, multisystem involvement and neurological symptoms. The diagnostic hypothesis is tested by biochemical and neurophysiological examination, traditional imaging (CT, MRI), functional imaging (functional MRI, nuclear magnetic (NM) spectroscopy, PET scan), morphological investigations (skin, nerve, muscle biopsies, etc.), biochemical investigations and molecular genetics. We have developed a cell and DNA bank for further pathogenetic studies. 
The diagnosis of rare disease is often a slow process for families, involving many hospitalizations in different hospitals. A study performed in USA showed that 6 years or more elapse before patients are correctly diagnosed. In our experience, deriving from the patients we have observed in our centre, the mean interval between the first clinical sign and diagnosis is 3-6 years for diseases with infantile onset and 4-10 years for those with later onset.

Table IV lists the consequences, nearly always irreparable, of late diagnosis. Improvements, in patient management, are thus needed to reduce the interval between the first clinical sign and diagnosis. Information on prevention strategies (prenatal diagnosis) needs to be made available to affected families in order to prevent the birth of other affected subjects.

Table IV - Consequences of late diagnosis.

Late onset of therapy

Genetic counseling no longer possible

Prenatal diagnosis not possible, leading to

birth of other affected subjects

Figure 1 shows the pedigrees of two families, one with fucosidosis and the other with metachromatic leukodystrophy. Both families had a first daughter (aged 6 and 3 , respectively) with severe spastic tetraparesis and epilepsy, initially misdiagnosed as sequelae of neonatal anoxia, but correctly diagnosed at 6 and 3 years of age, respectively. In the meantime, two sisters were born. They were diagnosed at 8 months and 1 year of age, respectively, before clinical symptoms became evident. Bone marrow transplantation, accepted by one family, produced good clinical and metabolic responses.
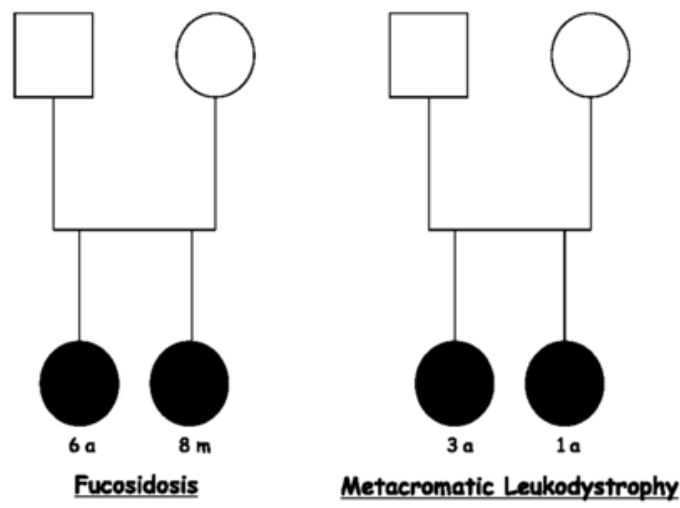

Fig. 1 Pedigree of two cases with late diagnosis of a neurometabolic diseases. In the families no prenatal diagnosis was performed, and a second case was born.

Late diagnosis is nearly always due to lack of information about the diseases, on the part of both family doctors and specialists. Health System structures are needed to obviate the problem of late diagnosis and to facilitate patient and family access (5). Table V lists the main problems we encountered among families and doctors.

Table V - Rare neurological diseases:

problems of doctors and families.

\begin{tabular}{|l|l|}
\hline \multirow{2}{*}{ Doctors: } & \begin{tabular}{l} 
Lack of information \\
\cline { 2 - 3 } Patients:
\end{tabular} \\
\hline & $\begin{array}{l}\text { Lack of knowledge of the subject } \\
\text { Lack of information on the disease } \\
\text { therapy }\end{array}$ \\
\cline { 2 - 2 } & $\begin{array}{l}\text { Lack of support groups } \\
\text { Services }\end{array}$ \\
\hline
\end{tabular}

\section{INFORMATION SERVICE POR RARE NEUROLOGICAL DISEASES}

The Information Service for Rare Neurological Diseases was established in Siena ten years ago. Like similar services, it provides information on clinical signs, examinations and tests needed for diagnosis, on referral centers for the different diseases in Italy and abroad, on recent research and addresses of family support associations. The service has two doctors on its staff and they can be contacted by telephone (+39 0577585763$)$, fax (+39 0577 40327), e-mail (federico@unisi.it; dotti@unisi.it ) and mail (U.O. Neurologia and Malattie Neurometaboliche, Servizio Informazioni Malattie Neurologiche Rare, Policlinico Universitario, Viale Bràcci 2, 53100 Siena, Italy).

We have received many requests from the different Italian regions and also from foreign countries. The majority of requests are from families, but we have recently had increasing contact with GPs and neurologists.

We are also organizing a link with the web page of the Italian Society of Neurology, in order to help Italian neurologists to become familiar with these disorders.

Table VI - Information requests for the different neurological diseases (\% in relationship to total).

\begin{tabular}{|l|l|}
\hline $20 \%$ Metabolic diseases & $7 \%$ Epilepsy \\
\hline $\begin{array}{l}20 \% \text { Neurodegenerative } \\
\text { disorders }\end{array}$ & $\begin{array}{l}5 \% \text { Cerebrovascular } \\
\text { diseases }\end{array}$ \\
\hline $10 \%$ Leucoencephalopathies & \begin{tabular}{l}
$4 \%$ Different syndromes \\
\hline $8 \%$ Myelopathies
\end{tabular} \\
\hline
\end{tabular}

\section{EDUCATION AND LIFELONG TRAINING}

One of the reasons of late diagnosis mentioned above was a lack of scientific information reaching family doctors and specialists. The reason for this is that rare diseases receive little attention in the medical school (5). Our personal interest in such topic is due to the presence of mentors who transferred to us their enthusiasm and expertise for these pathological conditions: my reference in this case goes to prof. Guazzi who has strongly supported our interest since his training in Belgium with prof. L. van Bogaert, and afterwards in Naples and in Siena.

In our opinion, it is essential that family doctors, dentists, speech therapists, physiotherapists, neurophysiologists, nurses and others professionals in health 
system acquire information about these disorders. They should at least be aware of the complexity of the problems, the different biological mechanisms that may lead to rare neurological diseases and the sources of information available to them. At least two hours of lessons must therefore be devoted to this topic in the various medical courses. Obviously, in post-graduate schools of neurology these disorders need to be treated more in details.

However, technological innovation and new therapies cannot be forthcoming unless young scientists are trained in basic and clinical research in this area, where incentives are limited, due to the few specific funds and to the difficulty in recruiting a sufficient number of patients for clinical trials (4). Steps have been taken to overcome these limits with the allocation of specific funds for rare diseases and orphan drugs in the framework of the Biomed projects.

To train personnel specifically for this type of research, a new PhD school (Mechanisms of Neurodegeneration, Neuroprotection and Neuroregeneration in Rare Neurological Diseases) was instituted at Siena University in 1999. The duration of the course is 4 years and links with other European universities (Paris, Oxford, Szeged) have been established. Its aim is to train young scientists for research into the mechanisms of neurodegeneration in rare diseases (such as neurometabolic diseases, especially mitochondrial and lysosomal metabolic diseases, in neurogenetic and neurodegenerative diseases) and into methods of neuroprotection and neuroregeneration. Rare neurological diseases are considered a good model for investigating the functions of the central and peripheral nervous systems and muscle. DIAGNOSIS OF RARE NEUROLOGICAL

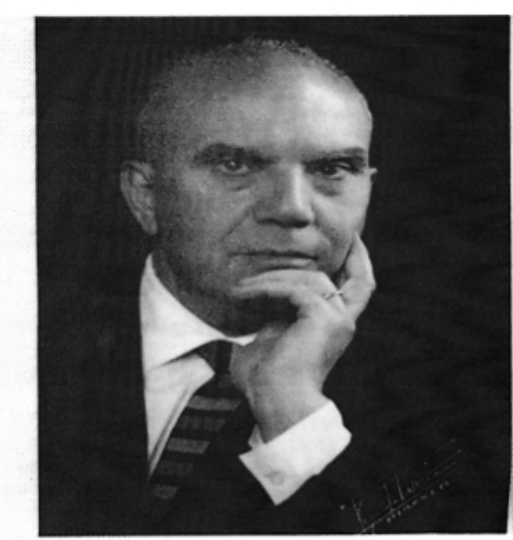

Left: Picture of Prof. Longo, director of the Dept. Neurology of Naples, dedicated to prof. Guazzi, described as a " bloodhound of rare diseases".
Below: Prof. Guazzi with prof. L. van Bogaert, during the honoris causa degree ceremony from the University of Siena.

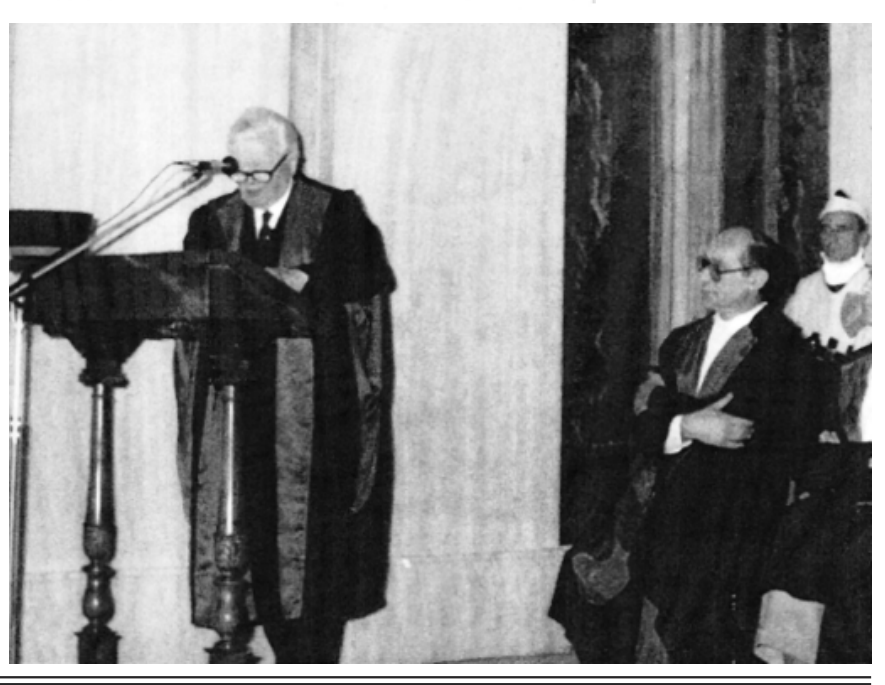

Table VII: Frequency of diagnosis of Rare Neurological diseases in our Unit (1995-2006)

\begin{tabular}{|l|c|c|c|c|c|c|}
\hline Year & $\begin{array}{c}\mathbf{N}^{\circ} \text { Ordinary } \\
\text { Hospitalization }\end{array}$ & Rare Diseases & $\begin{array}{c}\mathbf{N}^{\circ} \text { Day Hosp. } \\
\text { Hospitalization }\end{array}$ & $\begin{array}{c}\text { Rare } \\
\text { Diseases }\end{array}$ & $\begin{array}{c}\text { Tot. } \mathbf{N}^{\circ} \\
\text { hospitalization }\end{array}$ & $\begin{array}{c}\% \text { Rare Diseases } \\
\text { Rany }\end{array}$ \\
\hline $\mathbf{1 9 9 5}$ & $/ /$ & $/ /$ & 253 & $105(42 \%)$ & 253 & $83 \%$ \\
\hline $\mathbf{1 9 9 6}$ & $/ /$ & $/ /$ & 376 & $124(33 \%)$ & 376 & $77 \%$ \\
\hline $\mathbf{1 9 9 7}$ & $36(11 / 97)$ & $10(28 \%)$ & 261 & $85(33 \%)$ & 297 & $57 \%$ \\
\hline $\mathbf{1 9 9 8}$ & 238 & $62(26 \%)$ & 90 & $24(27 \%)$ & 328 & $74 \%$ \\
\hline $\mathbf{1 9 9 9}$ & 329 & $70(21 \%)$ & 44 & $12(27 \%)$ & 373 & $78 \%$ \\
\hline $\mathbf{2 0 0 0}$ & 319 & $91(29 \%)$ & 73 & $23(32 \%)$ & 392 & $71 \%$ \\
\hline $\mathbf{2 0 0 1}$ & 339 & $81(24 \%)$ & 109 & $22(20 \%)$ & 448 & $77 \%$ \\
\hline $\mathbf{2 0 0 2}$ & 296 & $67(23 \%)$ & 113 & $39(35 \%)$ & 409 & $74 \%$ \\
\hline $\mathbf{2 0 0 3}$ & 355 & $75(21 \%)$ & 133 & $51(38 \%)$ & 488 & $82 \%$ \\
\hline $\mathbf{2 0 0 4}$ & 391 & $88(23 \%)$ & 181 & $62(34 \%)$ & 572 & $49 \%$ \\
\hline $\mathbf{2 0 0 5}$ & 472 & $60(13 \%)$ & 184 & $50(27 \%)$ & 656 & $61 \%$ \\
\hline $\mathbf{2 0 0 6}$ & 391 & $40(10 \%)$ & 246 & $61(25 \%)$ & 637 & $54 \%$ \\
\hline Totale & 2775 & $604(19 \%)$ & 1817 & $597(29 \%)$ & 4592 & $71 \%$ \\
\hline
\end{tabular}


DISEASES IN SIENA

In the tables below, we report the diagnostic activity for the rare neurological diseases performed in the Unit of Neurology and Neurometabolic diseases during the years, showing the frequency of rare neurological diseases compared to other more frequent disorders (Table VII and Table VIII).

Table VIII: Diagnosis of Rare Neurological Diseases performed in our Unit in the last 15 years

\begin{tabular}{|c|c|}
\hline Disease & No. of Cases \\
\hline Spinocerebellar Disease & 151 \\
\hline Hereditary Neuropathies & 52 \\
\hline Mithocondrial Diseases & 52 \\
\hline Leukodystrophies & 52 \\
\hline Myotonic Dystrophies & 48 \\
\hline Cerebrotendinous Xanthomatosis & 30 \\
\hline Muscle Dystrophies & 28 \\
\hline Amyotrophic Lateral Sclerosis & 25 \\
\hline $\begin{array}{l}\text { Other multiple congenital syndromes } \\
\text { associated with mental retardation }\end{array}$ & 22 \\
\hline Huntington's Disease & 20 \\
\hline Idiopathic torsion Dystonia & 19 \\
\hline Hereditary Congenital Miopathies & 17 \\
\hline Lipid Storage Disorders & 12 \\
\hline MERRF & 11 \\
\hline Leber's Optic Atrophy & 9 \\
\hline Neurofibromatosis & 5 \\
\hline MELAS & 5 \\
\hline Arnold - Chiari Syndrome & 1 \\
\hline Adrenoleukodystrophy & 3 \\
\hline Mucolipidosis & 1 \\
\hline SCAD Deficiency & 1 \\
\hline Angelman's Syndrome & 2 \\
\hline Kearns - Sayre Syndrome & 3 \\
\hline Gangliosidosis & 2 \\
\hline Ehlers - Danlos Syndrome & 1 \\
\hline Tuberous Sclerosis & 1 \\
\hline Wilson's Disease & 3 \\
\hline Hereditary Coagulation Disorders & 4 \\
\hline Rett's Syndrome & 2 \\
\hline Narcolepsy & 1 \\
\hline Cranial Congenital Malformations & 2 \\
\hline Eals' Disease & 1 \\
\hline
\end{tabular}

In Table IX and Table $\mathrm{X}$ we describe the number of several biochemical tests of lysosomal enzyme activities, whose deficiency is linked to complex neurometabolic diseases with leucoencephalopathy ( galactocerebrosidase, absent in Krabbe disease; arylsulphatase A, absent

Table IX: Diagnosis of Krabbe Disease (galacto-cerebrosidase deficiency) and of Adrenoleucodystrophy performed in our laboratories within the 1996-2005 years.

\begin{tabular}{|c|c|c|}
\hline \multirow{2}{*}{} & \multicolumn{2}{|c|}{$1996-2005$} \\
\cline { 2 - 3 } & $\begin{array}{c}\text { Patients } \\
\text { examined }\end{array}$ & $\begin{array}{c}\text { Patients with } \\
\text { deficiency }\end{array}$ \\
\hline B-galactocerebrosidase & $\mathbf{4 0 7}$ & $\mathbf{1 6}$ \\
\hline & \multicolumn{2}{|c|}{$1999-2005$} \\
\cline { 2 - 3 } & $\begin{array}{c}\text { Patients } \\
\text { examined }\end{array}$ & $\begin{array}{c}\text { Patients with } \\
\text { deficiency }\end{array}$ \\
\hline $\begin{array}{c}\text { Long chain and very long } \\
\text { chain fatty acids } \\
\text { (VCLFA) }\end{array}$ & 191 & 6 \\
\hline
\end{tabular}

Disease

Congenital Ichthyosis

Gerstmann - Strauss Syndrome

Aneuploidy Chromosome Syndrome

Chromosomical Duplication Syndrome

Ito's Hypomelanosis

Amino Acid Disorders

Hereditary Retinal Dystrophies

Sjogren - Larsonn Syndrome

Gaucher's Disease

Neuroacanthocytosis

Marfan's Synrome

Polymyositis

Myoclonic Progressive Epilepsy

Cryoglobulinemia

Sturge - Weber Syndrome

Syringomyelia

Nemalinic Myopathy

Mini-multicore Myopathy

Tubular Aggregate Myopathy

Central core Myopathy

Myopathy with calpain deficiency

Myopathy with caveoline deficiency (MRD)

Merosin-Positive Congenital

Muscular Dystrophy

Autosomal Dominant inclusion body Myopathy

Bethlem Miopathy

Giant axonal Neuropathy

Seitelberger's Neuro axonal Dystrophy

Polyglucose Bodies Neuropathy

Minifascicular Neuropathy

Not classified Motor - Sensitive

Neuropathies

No. of Cases

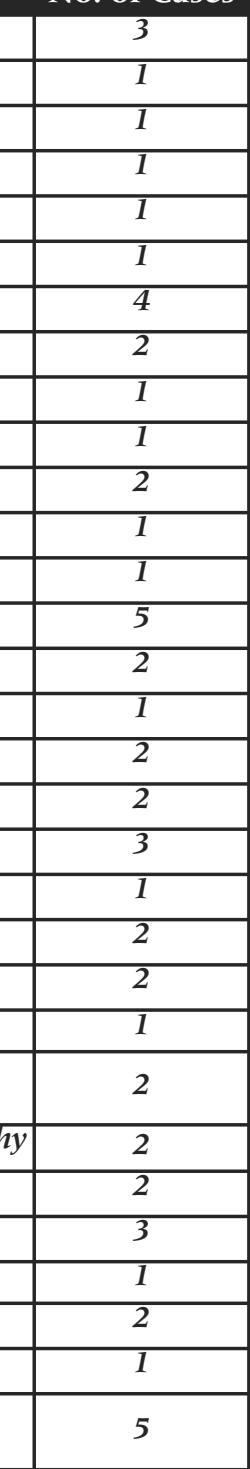

in metachromatic leucodystrophy) o serum metabolites as very long chain fatty acids, that is increased in adrenoleucodystrophy. We receive samples from many hospitals, often without a previous direct control of patients, explaining thus the low rate of positivity of tests.

Table X: Diagnosis of lysosomal disorders performed in our laboratories within 1996-2005 years.

\begin{tabular}{|c|c|c|c|}
\hline & \multicolumn{3}{|c|}{$1996-2005$} \\
\hline & $\begin{array}{l}\text { Patients } \\
\text { examined }\end{array}$ & $\begin{array}{l}\text { Patients with } \\
\text { total } \\
\text { deficiency }\end{array}$ & $\begin{array}{l}\text { Patients with } \\
\text { partial } \\
\text { deficiency }\end{array}$ \\
\hline alpha-fucosidase & 983 & 1 & - \\
\hline alpha-mannosidase & 983 & - & - \\
\hline alpha-galactosidase & 983 & 5 & $\cdot$ \\
\hline N-acetil-b-glucosaminidase & 983 & 4 & - \\
\hline $\begin{array}{l}\text { N-acetil-B-glucosaminidase } \\
\text { isoenzyme A }\end{array}$ & 983 & - & . \\
\hline B-glucuronidase & 983 & - & - \\
\hline alpha- $\mathrm{N}$-acetilgalactosaminidase & 983 & - & - \\
\hline arylsulphatase & 983 & 5 & 22 \\
\hline
\end{tabular}


Recently a Tuscan Registry of Rare diseases has been created, in which are collected all the patients observed in the different regional hospital and health structures. I personally coordinate the activities for Neurological diseases. Table XI shows the number of patients enclosed into the Registry until march 2008 in the different Hospitals: the highest amount of patients is reported to have been followed in Siena, which makes the city in this field more active than Florence and Pisa, considered to be the most important cities with biggest hospitals and Universities.

Table XI: Data from the Tuscany Register of Rare Diseases: Comparison between the most important Hospitals (Pisa, Florence and Siena) of the Region.
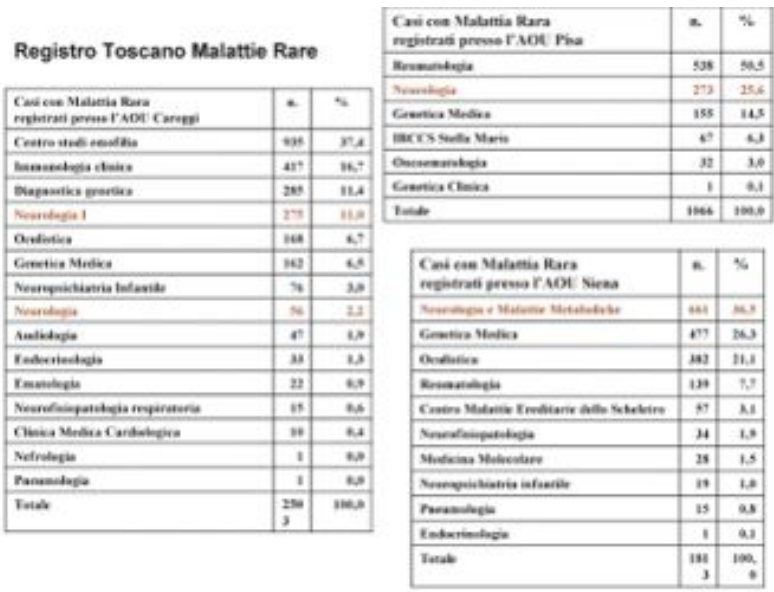

\section{PROBLEMS RELATED TO THERAPY: THE EXAMPLE OF CEREBROTENDINOUS XANTHOMATOSIS}

Certain rare neurological diseases, especially those linked to neurometabolic dysfunction, may benefit from different therapeutic strategies: for example diet, aimed to reduce toxic metabolites reaching the nervous System and other organs (phenylketonuria, aminoacidopathies, organic acidurias, mitochondrial diseases, etc.); drugs, designed to antagonize toxic substances; replacement therapy, aimed to correct enzyme deficiencies by providing vitamin cofactors or directly replacing the missing metabolites (carnitine in carnitine deficit, vitamin $\mathrm{E}$ in vitamin E deficiency, or enzyme therapy for Fabry, Pompe and other lysosomal diseases). However, the treatment of rare diseases presents many problems, particularly in relation to the development of new drugs (4).

Cerebrotendinous xanthomatosis (CTX) is a rare neurometabolic disease that we have investigated for many years (6). Almost all the Italian cases of this disease are treated in our centre. The clinical characteristics of CTX include progressive mental deterioration leading to dementia, juvenile cataract, epilepsy, myopathy, peripheral neuropathy, heart anomalies, osteoporosis and tendon xanthoma. These manifestations are secondary to a metabolic disorder of bile acid with low plasma concentrations of chenodeoxycholic acid and high amount of cholestanol, a cholesterol derivative that replaces cholesterol in the plasma membrane, rendering it unstable and dysfunctional. The metabolic condition is due to a deficiency of liver 27-hydroxylase activity. The gene coding for the enzyme has been identified and many mutations have recently been described, some of them by our group. It has been demonstrated that if normal bile acid concentrations are restored by administration of chenodeoxycholic acid (750 mg/day), serum and CSF levels of cholestanol decrease and clinical symptoms improve (7). This therapy, started at an early stage, is able to prevent the severe neurological impairment. Homozygotes can be diagnosed before symptoms appear by identifying mutations of the gene coding for 27-hydroxylase.

Chenodeoxycholic acid was used in the treatment of bile stones and was easely available in pharmacies. It became unavailable in Italy in 1995, with the introduction of other drugs, such as Ursodeoxycholic acid and simvastatin. Ursodeoxycholic acid does not reduce plasma levels of cholestanol and therefore cannot be used to treat CTX. Simvastatin is less effective than chenodeoxycholic acid in reducing plasma levels of cholestanol and has many side effects. As a result, our patients (more than 40), were suddenly deprived of a vital substance that prevented disease progression.

Fortunately we found a drug company that produces the substance for other purposes, and in collaboration with the our hospital pharmacy, we galenically prepared appropriate doses of the drug for our patients. The drug is now distributed to all patients periodically, enabling us to carry out clinical and biochemical monitoring, and making our referral centre therapeutic as well as diagnostic $(8,9,10)$.

The data gathered over the years have provided useful informations on absorption, metabolism and side effects of the drug in a significant group of patients, and on some of the metabolic pathways of cholesterol and cholestanol.

Fig.4: The main characteristics of cerebrotendinous xanthomatosis

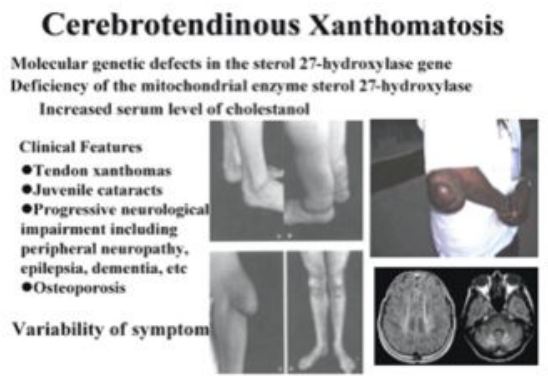

Fig 5: The main mutations of the CYP27Al gene, present in Cerebrotendinous xanthomatosis $(11,12)$

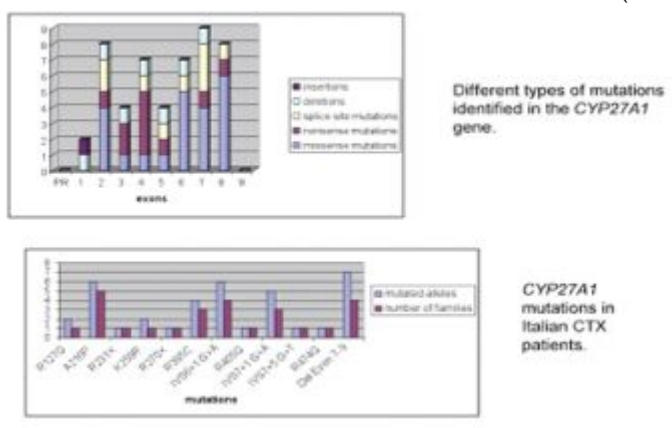


It is well known that chenodeoxycholic acid normalizes the levels of bile acids and consequently the serum and CSF amount of cholestanol, followed by a significant clinical improvement. Such treatment, if started as soon as possible and before the onset of clinical signs today possible in subjects where has been diagnosed by molecular techniques in affected families, is able to prevent the severe neurological symptoms.

Fig. 6: Effect of chenodeoxycholic acid treatment in Cerebrotendinous xanthomatosis. Improvement of cholestanol plasma levels and of neurophysiological parameters of peripheral nerves.
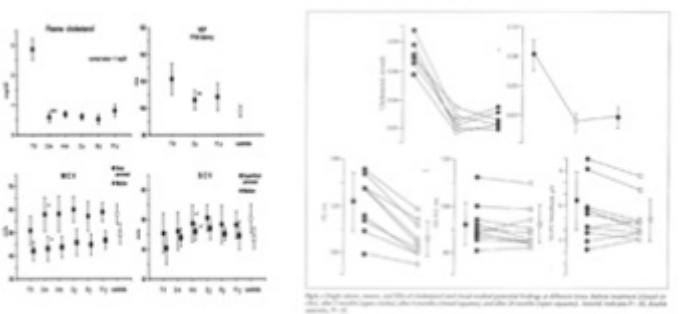

Cerebrotendinous xanthomatosis: 11 year treatment with Chenodeoxycholic acid in five patients. An electrophysiological study Mondelli M et al. J. Neurol. Sci. 190:2933, 2001

Table XII - Chenodeoxycholic acid Therapy in cerebrotendinous xanthomatosis.

Drugs previously available in pharmacies: Chenochol, Chenofalk, Chenoxyl, Fluibil

\begin{tabular}{l} 
Problems \\
\hline -Unavailable since 1995 \\
- Only Ursodeoxycholic acid available \\
- Ursodeoxycholic acid does not reduce \\
plasma cholestanol levels \\
- Galenica preparation by Siena hospital pharmacy \\
\hline \multicolumn{1}{c}{ Advantages } \\
- Centralized distribution allows clinical and \\
biochemical monitoring \\
\hline
\end{tabular}

\section{CONCLUDING REMARKS}

Our experience has taught us that in spite of many national and international initiatives undertaken to facilitate diagnosis, research and therapy of rare neurological diseases, much still needs to be done in support of these patients, who are twice unfortunate: first because they are ill and secondly because of the difficulty of obtaining medical care.

One of the aims of a modern society should be to ensure that basic and clinical research is conducted into this group of diseases, which can also be considered as useful models for understanding the normal functions of neurons, glial cells, muscle cells and so forth. It is also important to correctly address the investigation for diagnosis, therapy and prevention and that doctors and patients are provided with adequate information. These objectives can be reached by increasing funding, coordination of basic and applied research, availability of epidemiological data and disease records, and above all through collaboration between the doctors, biolo- gists and technicians working on these problems and patients and their families awaiting therapies to improve their quality of life.

I would like to conclude with two sentences who focused the attention on the study of rare diseases: the first is of W. Harvey in 1647 , reported by A. Garrod in 1928 (12). "Nature is nowhere accustomed more openly to display her secret mysteries than in cases where she shows traces after working apart from the beathen path; nor is there any better way to advance the proper practice of medicine than to give our minds to the discoveries of the usual law of nature by careful investigation of causes of rarer forms of diseases. For it has been found, in almost all things, that what they contain of useful or applicable is hardly perceived under we are deprived of them or they become deranged in some way".

The second is the title of a recent article by Talbot (13), "The study of rare diseases: butterfly collecting or an entrée to understanding common conditions?" . Who is involved in the clinical and research aspects of rare diseases, needs to be considered no more as a narcissist or butterfly collector, but instead, as a scientist investigating pathological models that may help to understand the physiopathology of the more common disorders.

\section{REFERENCES}

1)Viccaro G. Malattie rare e farmaci orfani. Pisa; Edizioni ETS, 2000 2)Thoene JG. Physycians' Guide to Rare Diseases. Montvale; Dowden Publishing Company Inc. 1995

3)Federico A. Guida alle Malattie Rare. Edizione italiana. Milan; Hyppocrates Edizioni

Medico Scientifiche, Milano, 1999

4)Wilson R. Rare diseases and the assesment of intervention: what sorts of clinical trials can use? J Inherit Metabol Dis. 24: 291-298, 2001

5)Federico A, Dotti MT. La programmazione politica e le malattie rare. In: Qualità e accreditamento e gestione delle Unità Operative in Neurologia, ed. V.Bonavita, A.Federico, L.Provinciali, V.Toso (Centro Scientifico Editoriale, Torino), Vol. 8, pg. 65-74, 2001

6)Federico A, Dotti MT. The Siena experience on rare neurological diseases: diagnosis, therapy and research model for investigations of central and peripheral nervous system and muscle. Functional Neurology 16, (suppl.4), 263-269, 2001.

7)Federico A, Dotti MT. Cerebrotendinous xanthomatosis. In: Vinken PJ, Bruyn GW. Eds Handbook of Clinical Neurology. Vol. 66. Amsterdam; Elsevier pg 599-613, 1996

8) Mondelli M, Rossi A, Scarpini C, Dotti MT, Federico A. Evoked potentials in cerebrotendinous xanthomatosis and effect induced by chenodeoxycholic acid. Arch. Neurol. 49: 469-475, 1992

9)Mondelli M, Sicurelli F, Scarpini C, Dotti MT, Federico A. Cerebrotendinous xanthomatosis: 11-year treatment with chenodeoxycholic acid in five patients. An electrophysiological study. J Neurol Sci. 190(12):29-33, 2001

10)Federico A, Dotti MT, Fleck JD. Cerebrotendinous xanthomatosis. Neurology ; 57:1743, 2001

11)Gallus GN, Dotti MT, Federico A. Clinical and molecular diagnosis of cerebrotendinous xanthomatosis with a review of the mutations in the CYP27A1 gene. Neurol Sci. 2006 Jun;27(2):143-9. Review.

12)Szlago M, Gallus GN, Schenone A, Patiño ME, Sfaelo Z, Rufa A, Da Pozzo P, Cardaioli E, Dotti MT, Federico A. The first cerebrotendinous xanthomatosis family from Argentina: a new mutation in CYP27A1 gene. Neurology. 2008 Jan 29;70(5):402-4.

13) A. Garrod: The lesson of rare maladies Lancet 1: 1055, 1928

14) Talbot $K$. The study of rare diseases: butterfly collecting or an entree to understanding common conditions? Pract. Neurol. 7: 210-211, 2007 